\title{
Non-traditional Religion, Hyper- Religiosity and Psychopathology: The Story of Ivan from Bulgaria
}

\author{
I. Mitrev and M. Y. Mantarkov
}

\subsection{Introduction}

The relationship between religion and psychiatry remains a difficult and contentious area [1]. There is a widespread view that religion boosts mental stability. However, in certain cases, extreme religiosity may undermine mental health [2]. Then again, psychotic disorders can present with religious delusions. In order to define a religious idea as delusional, it should exceed what is within the expected beliefs for an individual's background, including culture and education.

Hyper-religiosity may be considered a psychiatric disturbance at least according to the American Psychiatric Association's Diagnostic and Statistical Manual (the DSM), when it interferes with normal functioning. DSM offers what it describes as a descriptive (hence value-free) way of assessing mental health issues. Yet as the story of Ivan presented in this chapter illustrates, the judgments of dysfunction on which DSM's differentiation between normal hyper-religiosity and religious delusions critically depends are essentially value judgments. As such, as Ivan's story further illustrates, the differential diagnosis is considerably influenced by culture. The influence of cultural values is further complicated by the fact that in certain cases, religion or denomination is related to nationalism and there is thus a substitution of faith for identity.

We present, then, the story of Ivan, a young Bulgarian man, who converted to Orthodox Judaism, a religious denomination highly unusual in his country of birth.

\footnotetext{
I. Mitrev $(\bowtie) \cdot$ M. Y. Mantarkov

Department of Psychiatry and Medical Psychology, Medical University of Plovdiv, Plovdiv, Bulgaria

Clinic of Psychiatry and Medical Psychology, University Multiprofile Hospital for Active Treatment "Sveti Georgi", Plovdiv, Bulgaria e-mail: ivomitrev@gmail.com; mantarkov@gmail.com
} 


\subsection{Case History}

Ivan (not his real name) was an 18-year-old Bulgarian man, who completed only his elementary education and was currently unemployed.

Family history: Ivan had a paternal first cousin with schizophrenia; and his father was described as impulsive and explosive.

Bad habits: none reported.

Social conditions: Ivan's social conditions were adequate. He was currently living with his parents. They were not particularly religious Eastern Orthodox Christians; Ivan himself did not receive a religious education. He was an only child.

He was born at 37 weeks of gestation of a first normal pregnancy. His birth weight was $3000 \mathrm{~g}$. He was kept in a neonatal intensive care unit for 5 days. Neonatal jaundice was suspected. He started walking before the age of one and spoke his first words before 18 months. He was sent to nursery school at the age of two, where he adapted well. At three, he went to kindergarten, where he refused to participate in formal celebrations (some of them religious in nature, such as Christmas and Easter; but most of them secular). In his 2 years of preschool education he generally kept to himself.

He started school at seven together with his peers. He graduated from primary school (grades 1-4) with top marks. From grade 5 onwards his academic performance dropped drastically. He found school meaningless and often failed to do his homework assignments. He played a lot of computer games and wanted to become a professional player. From grade 2 through grade 7 he refused to eat meat. After his 7th grade he was admitted to a Vocational-technical school to study computer programming. He finished his 8th grade with passing grades. He did not complete his 9 th grade.

During his school years, although never showing signs of mental health issues, he exhibited a number of behavioural oddiites. As early as his first years of school he was described as squeamish and fastidious about food. He showered with baking soda, as he believed that soap was harmful. In his 5th grade he refused to wear underwear because it was too restrictive. He started wearing tracksuit bottoms instead.

In his 7th grade he became annoyed with his father's cough and yawns. He also became annoyed when people touched their eyes. He refused to be touched. After a conflict with his father he broke the television set and the remote control. On account of his refusal to attend school, the family saw an outpatient psychiatrist. Antipsychotic treatment with Haloperidol $1.5 \mathrm{mg} /$ day $P O$ was prescribed but Ivan refused to take the medication. Consequently another outpatient psychiatrist prescribed antipsychotic treatment (initially with Aripiprazole, followed by Risperidone). No significant effect was observed. He became vegan. After a conflict with his father, he and his mother moved out to live with his grandmother. Consequently he started living alone, because after a series of domestic conflicts, both his parents moved out. He hardly ever left the home. In the autumn of 2016 he was hospitalized in a psychiatric clinic and treated with Aripiprazole $10 \mathrm{mg} /$ day PO. He was discharged with the diagnosis Schizotypal personality disorder, "calm, often with loose associations 
and a tendency to form magical and symbolic thinking”. The recommended outpatient treatment was Omega-3 fatty acids and CBT (Cognitive Behavioral Therapy).

After discharge, he took no further psychotropic medications. Fear of death inspired an interest in religion. His interest in Christianity lasted a day; his interest in Islam-2 months. He even considered converting to Islam. Later that year, he became interested in Judaism; gradually his interest became stronger and he adhered with increasing rigor to religious rules. He became a follower of the Orthodox Jewish movement, seen by some as a sect.

He now only eats kosher foods. A year ago he threw away a keychain of his father's with a cross. He confided that he wanted to go to Israel to study Judaism in Yeshiva living on donations. Because of his identification with Orthodox Judaism, Ivan has not had his hair cut or shaved his beard ever since his conversion. He has avoided touching or even looking at women. He has spent most of his time reading religious texts and watching religious videos on the internet. In the past 6 months he has not socialized with anyone other than his parents outside his religion. He has been in touch with rabbis on the internet.

Ever since, Ivan has had hyper-religious and possibly delusional ideas about food. He holds that food had to be prepared in the daylight "against daemons." He spends hours preparing food so it is not "contaminated" and eats separately. This has to be done, because a mezuzah (a piece of parchment with holy writings that repels evil) had not been fixed to the door.

He has shown other hyper-religious behaviors. For example, he broke an icon in the office of an outpatient psychiatrist, which he did not regret, claiming it depicted "idols". The outpatient psychiatrist diagnosed him with paranoid schizophrenia and recommended to Ivan's parents compulsory treatment in a psychiatric clinic. However, when they met with the inpatient psychiatrist, they came to the shared decision that voluntary hospitalization in the clinic would be more appropriate. Ivan consequently signed an informed consent form. He explained: "I am here, because I don't want to study and work." He agreed to take one tablet of an antipsychotic medication daily.

Psychological assessments of personality, thought, emotions and volition were conducted in the clinic: "Results from the personality questionnaire (Minnesota Multiphasic Personality Inventory-MMPI-2): due to high scores on one of the validity scales, which is interpreted as a sign of strong defenses, the profile is considered invalid. Thought: no notable disturbances in the rate and form of thought; the content of thought is dominated by religious beliefs and attitudes belonging to an orthodox movement in Judaism, which are not in keeping with the local religious and sociocultural background.

It is in terms of his religion that Ivan explains his thinking and behavior, including the adherence to certain rules and laws about bodily and social functioning that are significantly different from those of modern Bulgarian society. He believes he is governed by high moral standards and denies any hostility or negative impulses to others whatsoever. He denies delusional, depressive, aggressive and suicidal ideas. Abstract thinking: he finds no difficulties with the formation of antonyms, the interpretation of proverbs and with arithmetic operations. Emotions: results from Zung 
Self-Rating Depression Scale- no evidence of depression; results from Hamilton Anxiety Rating Scale-no evidence of anxiety.

A conversation with Ivan's father revealed information about conflicts and difficulties in Ivan's upbringing as well as elements of controversy and inconsistency in his thinking and behavior in his childhood, with a tendency to manipulate and be manipulated.

Conclusion: Ivan gives the impression of a young man looking for answers to existential questions as well as for intimacy, security and belongingness as part of identifying the parameters of his own identity. He declares insight. He confides that he intends and plans to join a religious community and shows flexibility with different ways of coping under different circumstances. Family therapy was recommended."

Laboratory findings: mild alimentary anemia.

Computed tomography scanning of the head and posterior cranial fossa without contrast: normal.

In the clinic Ivan was treated with Olanzapine $10 \mathrm{mg} /$ day PO. No significant change in his mental condition was observed. During his hospital stay Ivan avoided eye contact with the other patients and refused to eat any of the hospital food. He asked: "What are you treating me for? Are you treating my religion?" He stated: "This is the only religion without mistakes." However, as to the 'mistakes' of other religions, he could only point out minor inconsistencies, such as the incorrect chronology of an event or a misnomer of a town in their holy books.

In a clinical staff meeting the diagnoses Schizoid personality disorder, Schizotypal personality disorder, Delusional disorder and Paranoid schizophrenia, were discussed and Schizotypal personality disorder was accepted.

This story has no happy ending at least as yet. By the time of discharge the clinicians had not been able to form a working diagnostic and therapeutic alliance with Ivan. On discharge he refused family therapy and said: "Now, I am going to be even more religious, and I am going to Israel."

\subsection{The Values Arising in This Story}

The principal and arguably only value held by Ivan was his religion; he was obsessed with it. To defend this value, he went to extremes, for example, by breaking the icon in the office of the outpatient psychiatrist in an act of iconoclasm. He refused to work and did not want to study anything but the religion to which he had converted.

As to the values of Ivan's parents, they wanted their only child to stay in Bulgaria, to study and to work. They thought their son needed to take psychotropic medications. On account of this and on the advice of the outpatient psychiatrist, they considered compulsory treatment, which would have seriously compromised the principle of autonomy.

The psychiatrist viewed breaking the icon as a sign of severe psychopathology. In this, he was thinking of the DSM's criteria of clinical significance as offering an evidence-based way of differentiating psychopathology from normal 
hyper-religiosity. But his diagnostic assessment was influenced by value judgments. The relevant DSM criterion is in this instance 'impairment of social functioning': surely, the psychiatrist assumed, breaking my icon is a sign of social dysfunction! But in this, he was drawing without recognizing it on (mainly implicit) value judgments. To take a related example, someone who leaves his home and work and goes off to meditate in the desert may be thought to be functioning well in a society that values religious retreat, but to be functioning badly in a society that is more workoriented. One implication of this, relevant to the outcome of Ivan's story is that maybe he will function better in another environment - why not a religious community in Israel?

Interestingly, the values of the clinical psychologist in this respect were different from those of the psychiatrist. As he (the psychologist) put it: "Ivan is not the typical young man of today, but I don't think he has a mental disorder." This is important because it underscores the significance of multidisciplinary assessment in coming to a balanced judgment between conflicting diagnostic values in a given case (see Introduction to this Part).

Overall, therefor, there are a number of conflicting values in play here that crucially influence how Ivan's story is understood and what is done about it. The outpatient psychiatrist-influenced in his application of DSM's criteria of clinical significance by his own implicit values-diagnosed Ivan with paranoid schizophrenia, which necessitates antipsychotic therapy, even at the (potential) cost of compulsory treatment. Guided by his own religious values, Ivan did not think he had a mental disorder, and so he refused to take medications (later as a compromise he agreed to take one pill a day for a limited period of time). The inpatient psychiatrist sought to balance these conflicting values by offering Ivan and his parents a compromise solution-voluntary inpatient treatment in a psychiatric clinic.

With regard to treatment, the inpatient psychiatrist was hesitant whether to prescribe antipsychotic therapy, as he did not expect it to be particularly effective in a patient with a personality disorder; he nonetheless prescribed an antipsychotic for the duration of Ivan's hospitalization. The clinical psychologist, who did not think that Ivan had a mental disorder, recommended family therapy, but Ivan refused to attend. His parents were outraged by the psychologist's opinion: they commented, "He said, there is nothing wrong with him". True, they were surprised by the lack of efficacy of antipsychotic therapy. But their reaction to this was that they expected the psychiatrist and psychologist to "persuade" Ivan "to not be a religious fanatic."

\subsection{The Influences of Culture on This Story}

Bulgarian society is not particularly religious [3]. Over-engagement in religious activities is not approved by society. Most Bulgarians describe themselves as Eastern Orthodox Christians, abide by traditional ritual practices, but do not live an orthodox way of life [4]. Ivan's hyper-religiosity was thus naturally seen as falling outside accepted norms of behavior. 
In Bulgaria, it is accepted that presenting oneself as Orthodox (Christian) is a sign of national identity. The Bulgarian Orthodox Church was a factor in the survival of the Bulgarian people under the Ottoman rule (1396 to 1878) as well as in the Bulgarian national liberation movement (mid 1850s-1878 ${ }^{1}$ ). The Orthodox Church has thus invariably been associated with nationalism and the state [5]. In 1879, the Tarnovo Constitution formally established the Bulgarian Orthodox Church as the national religion of the nation. Judaism, on the other hand, is usually considered the ethnic religion of the Jewish people. It could be argued that this substitution of faith for national identity was responsible for the mainly negative attitudes to Ivan.

A further cultural factor driving these negative attitudes is likely to have been the generally unfavorable attitude of the Bulgarian Orthodox Church to other religions and religious denominations. Recently, the Pope visited Bulgaria. The Holy Synod and the patriarch welcomed him coldly. A metropolitan bishop stated: "The visit of the Roman Pope is a political act. Its aim is to unite all churches around Rome so that when the Antichrist comes, the Pope can meet him." Bulgarian society as a whole does not approve of conversion to religions that are not traditional for the country. Again, then, Ivan was very much out of step with his society.

Being out of step in this way came to a head when Ivan broke the icon in the outpatient psychiatrist's office. The psychiatrist in question found it appropriate to put an orthodox icon in his office as "a spiritual symbol" even though it was visited by patients of different religions and denominations, as well as by atheists. A religious belief can be classified as delusional when it is idiosyncratic, rather than accepted within a particular culture or subculture. This undoubtedly contributed to the outpatient psychiatrist's view that Ivan had religious delusions.

There were also wider Bulgarian values in play. First, as to their children, Bulgarians have always strived to give them the best possible education. Ivan's unwillingness to study in a secular school was thus considered by his parents, in line with the majority of society and some psychiatrists, to be a sign of psychopathology. Second, as to work, it can generally be argued that Bulgarian society is workoriented and disapproves of people who do not work. Again, Ivan found himself at odds with this widely held cultural value, thus adding to the evaluation of his behavior as abnormal.

\subsection{Conclusions}

It is evident that Bulgarian cultural values influence the way people (including mental health professionals); see the story of Ivan. The diagnostic judgments of mental health professionals are considerably influenced by culture. Diagnostic differences attest to the significance of multidisciplinary assessment in coming to a balanced judgment between conflicting diagnostic values.

\footnotetext{
${ }^{1}$ After the Crimean War the Bulgarian struggle for liberation evolved into a national liberation movement. In the late 1860s it entered a new, higher stage.
} 
The story of Ivan also illustrates that the judgments of dysfunction on which DSM's differentiation between normal hyper-religiosity and religious delusions critically depends are essentially value judgments.

\section{References}

1. Fulford KWM. Religion and psychiatry: extending the limits of tolerance. In: Bhugra D, editor. Psychiatry and religion: context, consensus and controversies. London: Routledge and Kegan Paul; 1996.

2. Van Praag HM. God's champions and adversaries: about the borders between normal and abnormal religiosity. In: Verhagen PJ, Van Praag HM, López-Ibor JJ, Cox J, Moussaoui D, editors. Religion and psychiatry: beyond boundaries. Hoboken, NJ: Wiley; 2010.

3. Nazarska G, Shapkalova S. Study of religious values in present Bulgaria. In: Krikoryan R, Slavcheva K, Penou S, editors. Humanism, science, religion—values, paradigms and challenges in interreligious relations. Sofia; 2015.

4. Витанов Р. Религиозността на съвременния българин. In: Омарчевски А, Макариев П, editors. Християнство и философия. София: Парадигма; 2014. (Vitanov R. The Religiousness of Modern Bulgarians. In: Omarchevski A, Makariev P, editors. Christianity and Philosophy. II. Sofia: Paradigm; 2014).

5. Kushelieva Z. Развитие на отношенията между църквата и държавата в България. Kritische Zeitschrift für überkonfessionelles Kirchenrecht. 2016;3:39-44. (Kushelieva Z. Development of the Relations between the Church and the State in Bulgaria. Kritische Zeitschrift für überkonfessionelles Kirchenrecht. 2016(3):39-44).

Open Access This chapter is licensed under the terms of the Creative Commons Attribution 4.0 International License (http://creativecommons.org/licenses/by/4.0/), which permits use, sharing, adaptation, distribution and reproduction in any medium or format, as long as you give appropriate credit to the original author(s) and the source, provide a link to the Creative Commons license and indicate if changes were made.

The images or other third party material in this chapter are included in the chapter's Creative Commons license, unless indicated otherwise in a credit line to the material. If material is not included in the chapter's Creative Commons license and your intended use is not permitted by statutory regulation or exceeds the permitted use, you will need to obtain permission directly from the copyright holder.

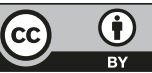

